\title{
Pretreatment with hyperbaric oxygen and its effect on neuropsychometric dysfunction and systemic inflammatory response after cardiopulmonary bypass: A prospective randomized double-blind trial
}

\author{
Joseph Alex, MD, MRCS, ${ }^{a}$ Gerard Laden, BSc, ${ }^{\text {b }}$ Alex R. J. Cale, MD, FRCS, ${ }^{\text {a }}$ Sean Bennett, MD, FRCA, \\ Kenneth Flowers, BSc, PhD, ${ }^{d}$ Leigh Madden, BSc, PhD, ${ }^{e}$ Eric Gardiner, BSc, PhD, \\ Peter T. McCollum, MD, FRCS, PhD, ${ }^{g}$ and Steven C. Griffin, MD, FRCS ${ }^{\mathrm{C}}$
}

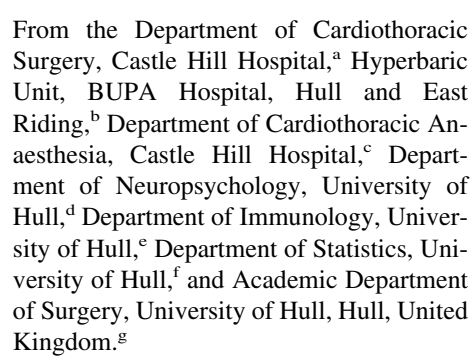

Read at the Eighty-fifth Annual Meeting of The American Association for Thoracic Surgery, San Francisco, Calif, April 10-13, 2005.

Received for publication March 10, 2005; revisions received July 11 , 2005; accepted for publication Aug 2, 2005.

Address for reprints: Joseph Alex, MD, MRCS, The Cottage, Main Road, Covenham St Bartholomew, Louth, LN11 OPF, UK (E-mail: mrjosephalex@yahoo.co.uk).

J Thorac Cardiovasc Surg 2005;130:1623-30 $0022-5223 / \$ 30.00$

Copyright $\odot 2005$ by The American Association for Thoracic Surgery

doi:10.1016/j.jtcvs.2005.08.018
Objective: Animal studies have shown that pretreatment with hyperbaric oxygen can induce central nervous system ischemic tolerance and also modulate the inflammatory response. We evaluated this therapy in patients undergoing cardiopulmonary bypass.

Methods: Sixty-four patients were prospectively randomized to group A ( $\mathrm{n}=31$; atmospheric air, 1.5 atmospheres absolute) or group B ( $\mathrm{n}=33$; hyperbaric oxygen, 2.4 atmospheres absolute) before on-pump coronary artery bypass grafting. Age, sex, body mass index, diabetes, hypertension, smoking, coronary disease severity, left ventricular function, Parsonnet score, Euroscore, bypass time, myocardial ischemia time, and number of grafts were comparable in both groups. Canadian Cardiovascular Society angina, New York Heart Association dyspnea, and previous myocardial infarction were significantly higher in group B. Inflammatory markers were analyzed before surgery and 2 and 24 hours after bypass. Neuropsychometric testing was performed 48 hours before surgery and 4 months after surgery and included trail making A and B, the Rey auditory verbal learning test, grooved peg board, information processing table A, and digit span forward and backward. Neuropsychometric dysfunction was defined as more than 1 SD deterioration in more than 2 neuropsychometric tests. Chi-square tests, Fisher tests, $t$ tests, and analysis of variance were used as appropriate for statistical analysis.

Results: Group A had a significant postoperative increase in the inflammatory markers soluble E-selectin, CD18, and heat shock protein 70. This was not observed in group B. Neuropsychometric dysfunction was also significantly higher in group A compared with group B. There was no difference in any other early postoperative clinical outcome.

Conclusions: Our results seem to indicate that pretreatment with hyperbaric oxygen can reduce neuropsychometric dysfunction and also modulate the inflammatory response after cardiopulmonary bypass. However, further multicenter randomized trials are needed to clinically evaluate this form of therapy.

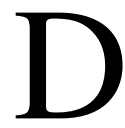
espite advances in surgical technique and bypass technology, there is a high incidence of neuropsychometric dysfunction and systemic inflammatory response after cardiac operations. Irrespective of the cause of injury, inflammatory cytokines released after the primary event trigger leukocyte activation and 


\section{Abbreviations and Acronyms \\ ATA $=$ atmospheres absolute \\ HADS $\quad=$ hospital anxiety and depression scale \\ HSP $\quad=$ heat shock protein \\ ICAM = intercellular adhesion molecule \\ IL $\quad=$ interleukin \\ $\mathrm{TNF} \quad=$ tumor necrosis factor \\ sE-selectin $=$ soluble E-selectin \\ $\mathrm{sP}$-selectin $=$ soluble P-selectin}

free radical release, causing secondary damage and extension of injury. Thus, modulating inflammatory molecules has the potential benefit of limiting leukocyte-mediated extension of injury. This was exemplified in animal experiments in which a reduction in cortical infarct size after ischemic injury was noted with inhibition of adhesion molecules. $^{1-4}$

Currently, hyperbaric oxygen is used as adjunctive therapy to treat ischemic, traumatic, air-embolic, carbon monoxideinduced, and radiation-induced brain injury. Although thus far limited to postinjury treatment, experimental animal studies have revealed that pretreatment ${ }^{5-8}$ with hyperbaric oxygen can induce central nervous system ischemic tolerance and reduce infarct volume and functional deficit. Both animal and human studies have shown that the modality reduces leukocyte sequestration, ${ }^{9,10}$ tumor necrosis factor (TNF)$\alpha,{ }^{10-13}$ interleukin (IL)-6, ${ }^{13}$ intercellular adhesion molecule (ICAM)-1, ${ }^{14,15} \mathrm{CD} 18,{ }^{16,17}$ tissue myeloperoxidase, ${ }^{18,19}$ and lipid peroxidation ${ }^{20}$ during inflammation. The aim of our study was to investigate whether these beneficial effects could be applied to patients undergoing cardiopulmonary bypass.

\section{Materials and Methods}

Ethics approval was obtained from the local regional ethics committee and the National Health Service research and development department of the hospital before this prospective randomized double-blind study was started. From January 2003 to January 2004, 64 patients scheduled to undergo on-pump coronary revascularization were recruited for the trial. Exclusion criteria included emergency operation, age older than 80 years, previous cerebrovascular disease, poor English language skills, learning difficulty, visual or hearing impairment, claustrophobia, history of pneumothorax, middle ear disease, and immunosuppressive or steroid therapy. After fully informed voluntary consent, patients were randomized either to the control group (group A) or to the hyperbaric oxygen group (group B) by using computer-generated randomization. The overall recruitment rate was $83.9 \%$, and there were no crossovers between the 2 groups.

Patients in both groups had 3 sessions in the hyperbaric chamber 24,12 , and 4 hours before cardiopulmonary bypass. The session sequence for group A consisted of slow pressurization over 10 minutes to 1.5 atmospheres absolute (ATA), 30 minutes in a clear plastic hood supplying atmospheric air, and 5 minutes out of the hood, followed by a further 30 minutes back in the hood, at the end of which slow depressurization over 25 minutes to 1 ATA (normal atmospheric pressure) was accomplished. The session sequence for group B consisted of slow pressurization over 10 minutes to 2.4 ATA, 30 minutes in a clear plastic hood supplying $100 \%$ oxygen, and 5 minutes out of the hood, followed by a further 30 minutes back in the hood, at the end of which slow depressurization over 25 minutes to 1 ATA was accomplished. The pressure and duration for each group was based on the optimum effect noted in previous studies ${ }^{9-19}$ and patient safety considerations. The anesthetic, bypass, and operative techniques were standardized in all patients. Intermittent fibrillatory arrest was used for myocardial protection. A Stockert SIII roller pump (Stöckert Instrumente GmbH, Munich, Germany) with a hollow-fiber membrane oxygenator with an integral hard shell venous cardiotomy reservoir (Avant Phisio/M; Dideco SpA, Mirandola, Italy) was used for cardiopulmonary bypass. A 38- $\mu \mathrm{m}$ arterial line filter (Affinity352; Medtronic, Inc, Minneapolis, Minn) was used in all cases. Moderate systemic hypothermia of $35^{\circ} \mathrm{C}$ was maintained during bypass, and rewarming was commenced during the last bottom-end anastomosis.

The laboratory analysis of inflammatory markers was performed by immunologists at the Department of Immunology, University of Hull, who were blinded to the groups. Markers of inflammatory response measured included cytokines (TNF- $\alpha$, IL-6, and IL-8), soluble adhesion molecules (soluble E-selectin [sE-selectin], soluble P-selectin [sP-selectin], and soluble ICAM1), the leukocyte-bound adhesion molecule CD18, and the stress response protein heat shock protein (HSP)-70. Blood for analysis was drawn from the central venous line at 3 time points: before skin incision and 2 and 24 hours after cardiopulmonary bypass. Quantitative enzyme-linked immunosorbent assay was used for measuring IL-6 (KAC1261; BioSource International Inc, Camarillo, Calif), IL-8 (KAC1301; BioSource International Inc), TNF- $\alpha$ (KAC1751; BioSource International Inc), sE-selectin (KHS2011; BioSource International Inc), sP-selectin (KHS2021; BioSource International Inc), soluble ICAM-1 (KHS5411; BioSource International Inc), and HSP-70 (EKS-700; Stressgen Biotechnologies Corporation, Victoria, British Columbia, Canada). An Anthos 2010 microtiter plate reader (Anthos Labtec Instruments $\mathrm{GmbH}$, Wals, Austria) was used for the spectrophotometric measurement with Stingray software (Stingray Software Inc, Devon, United Kingdom) for analyses. Fluorescein-tagged anti-human CD18 antibodies (MCA503; Serotec Ltd, Kidlington, Oxfordshire, United Kingdom) were used for quantitative flow cytometric estimation of leukocyte CD18 by using a BD FACSCalibur analyzer (BD Biosciences Pharmingen, San Diego, Calif) with CellQuest software (BD Biosciences). To eliminate the effect of hemodilution caused by the priming solution in the pump and from intravenous fluids administered during and after surgery, the actual measured plasma levels of inflammatory molecules at 2 and 24 hours after bypass were multiplied by the correction factor described by Roth-Isigkeit and associates. $^{20}$

$$
\text { Correction factor }=\text { phct }_{\mathrm{ti}} / \text { phct }_{\mathrm{t} 0} \text {, }
$$

where phct indicates plasma hematocrit $(100$ - red blood cell 
TABLE 1. Comparison of demographic and perioperative factors

\begin{tabular}{|c|c|c|c|}
\hline Variable & Group A & Group B & $P$ value \\
\hline Age & $65.9 \pm 1.7$ & $66.2 \pm 1.5$ & .9 \\
\hline \multicolumn{4}{|l|}{ Sex } \\
\hline Male & $83.9 \%$ & $87.5 \%$ & .7 \\
\hline Female & $16.1 \%$ & $12.5 \%$ & \\
\hline Body mass index $\left(\mathrm{kg} / \mathrm{m}^{2}\right)$ & $26.7 \pm 0.6$ & $27.3 \pm 0.8$ & .5 \\
\hline Unstable angina & $6.5 \%$ & $6.3 \%$ & .9 \\
\hline Previous myocardial infarction & $9.7 \%$ & $31.3 \%$ & .03 \\
\hline Left main stem disease & $29 \%$ & $18.8 \%$ & .3 \\
\hline \multicolumn{4}{|l|}{ Coronary disease severity } \\
\hline Single & $12.9 \%$ & $3.1 \%$ & \\
\hline Double & $32.3 \%$ & $21.9 \%$ & \\
\hline Triple & $54.8 \%$ & $75 \%$ & .2 \\
\hline \multicolumn{4}{|l|}{ Left ventricular function } \\
\hline Good & $87.1 \%$ & $81.2 \%$ & \\
\hline Moderate & $9.7 \%$ & $12.5 \%$ & \\
\hline Poor & $3.2 \%$ & $6.3 \%$ & .9 \\
\hline Hypertension & $67.7 \%$ & $62.5 \%$ & .7 \\
\hline Diabetes mellitus & $12.9 \%$ & $15.6 \%$ & .8 \\
\hline Peripheral vascular disease & $6.3 \%$ & $6.1 \%$ & .9 \\
\hline Parsonnet score & $6.5 \pm 1.2$ & $7.2 \pm 1$ & 6 \\
\hline EuroSCORE & $3.3 \pm 0.4$ & $3.5 \pm 0.3$ & .7 \\
\hline \multicolumn{4}{|l|}{ No. of grafts } \\
\hline 1 & $16.1 \%$ & 0 & \\
\hline 2 & $35.5 \%$ & $37.5 \%$ & \\
\hline 3 & $48.4 \%$ & $62.5 \%$ & .07 \\
\hline $\begin{array}{l}\text { Myocardial ischemia time } \\
\text { (min) }\end{array}$ & $23.5 \pm 1.5$ & $24.8 \pm 1.4$ & .5 \\
\hline $\begin{array}{l}\text { Cardiopulmonary bypass time } \\
\text { (min) }\end{array}$ & $50.1 \pm 4.3$ & $52.1 \pm 3$ & .7 \\
\hline CVA/TIA & 0 & 0 & \\
\hline Mortality & 0 & 0 & \\
\hline $\begin{array}{l}\text { Neuropsychometric test-retest } \\
\text { interval (d) }\end{array}$ & $120.1 \pm 3.6$ & $126.3 \pm 4.3$ & .3 \\
\hline $\begin{array}{l}\text { Verbal IQ: WTAR standardized } \\
\text { score }\end{array}$ & $101.3 \pm 2.8$ & $95.8 \pm 2.9$ & .2 \\
\hline Nonverbal IQ: Raven matrices & $29.7 \pm 0.7$ & $30.1 \pm 0.8$ & .7 \\
\hline $\begin{array}{l}\text { Preoperative (HADS) anxiety } \\
\text { score }\end{array}$ & $6.7 \pm 0.8$ & $5.6 \pm 0.8$ & .3 \\
\hline $\begin{array}{l}\text { Postoperative (HADS) anxiety } \\
\text { score }\end{array}$ & $4.9 \pm 0.6$ & $4.6 \pm 0.6$ & .7 \\
\hline $\begin{array}{l}\text { Preoperative (HADS) } \\
\text { depression score }\end{array}$ & $4.6 \pm 0.6$ & $3.2 \pm 0.4$ & .1 \\
\hline $\begin{array}{l}\text { Postoperative (HADS) } \\
\text { depression score }\end{array}$ & $3.3 \pm 0.5$ & $2.3 \pm 0.4$ & .2 \\
\hline
\end{tabular}

Data are mean \pm SE unless otherwise noted. CVA, Cerebrovascular accident; TIA, transient ischemic attack; WTAR, Wechsler Test of Adult Reading; HADS, hospital anxiety and depression scale.

hematocrit percentage), ti indicates the value at the time of sampling, and t0 indicates the value at baseline.

Neuropsychometric assessment was performed by neuropsychologists at the Department of Neuropsychology, University of Hull, who were blinded to the groups. All the recommendations on conducting neuropsychometric assessment issued by the 1994 conference on central nervous system dysfunction after cardiac surgery $^{21}$ were followed. The assessments were performed 48 hours before surgery and approximately 4 months after surgery. The Wechsler Test of Adult Reading and Raven colored progressive matrices were used to assess verbal and nonverbal IQ, respectively, during preoperative testing. The self-reported hospital anxiety and depression scale (HADS) was used for mood assessment before both preoperative and postoperative assessment. The 7-test neuropsychometric assessment battery included the adult memory and information-processing table A, digit span forward, and digit span backward, in addition to the 4 recommended ${ }^{21}$ core tests (trail making A, trail making B, grooved peg board, and the Rey auditory verbal learning test).

SPSS version 11 for Windows (SPSS Inc, Chicago, Ill) was used for statistical analysis. Demographic and perioperative data were analyzed by using the unpaired $t$ test for continuous variables and the $\chi^{2}$ or Fisher test, as appropriate, for discrete variables. Nonparametric analysis of variance was used to compare sequential change during the 3 time points for inflammatory markers. Spearman correlation analysis of postoperative increases in inflammatory markers with age, duration of cardiopulmonary bypass, and duration of myocardial ischemia was also performed. The standard deviation index method was used to analyze neuropsychometric outcome. This was one of the methods recommended by the 1994 conference $^{21}$ and has been validated by previous studies. ${ }^{22,23}$ A postoperative deterioration of greater than $1 \mathrm{SD}$ from the preoperative score in 2 or more tests $(>28 \%$ of the tests) was considered significant neuropsychometric impairment. For the peg board test with 2 subtests, a 1 SD decline in either of the subtests was considered significant, whereas for the Rey Auditory Verbal Learning Test, a 1 SD decline in any 2 or more of the 4 subtests was considered significant. The $\chi^{2}$ test was used to compare the 2 groups for statistical significance. Logistic regression analysis on the pooled data was performed to see whether we could identify any predictors of neuropsychometric dysfunction.

\section{Results}

Both groups were comparable (Table 1) in terms of age, sex ratio, body mass index, unstable angina, coronary disease severity, left ventricular function, hypertension, diabetes mellitus, peripheral vascular disease, Parsonnet score, Euroscore, number of grafts, cardiopulmonary bypass time, and myocardial ischemia time. Significantly more patients $(31.3 \%)$ in group B had previous myocardial infarction compared with group A $(9.7 \%)$. The postoperative trends in inflammatory mediators are depicted in Table 2. Levels of sE-selectin, IL-6, IL-8, CD18, TNF- $\alpha$, and HSP-70 peaked at 2 hours and declined at 24 hours. The sP selectin level showed a declining trend, whereas ICAM-1 initially declined at 2 hours before reaching preoperative levels at 24 hours. Analysis of variance revealed a significant postoperative increase in sE-selectin $(P=.05), \mathrm{CD} 18(P=.001)$, and HSP-70 $(P=.007)$ in group A that was not seen in group $\mathrm{B}(P=.2, P=.1$, and $P=.2$, respectively). The postoperative increase in IL-6, IL-8, ICAM-1, and TNF- $\alpha$ 
TABLE 2. Comparison of inflammatory markers and correlation analysis of postoperative increase with age, cardiopulmonary bypass time, and myocardial ischemia time

\begin{tabular}{|c|c|c|c|c|c|c|c|c|c|c|c|c|c|c|}
\hline \multirow[b]{2}{*}{ Variable } & \multicolumn{4}{|c|}{ Group A } & \multicolumn{4}{|c|}{ Group B } & \multicolumn{2}{|c|}{ Age } & \multicolumn{2}{|c|}{ CPB time } & \multicolumn{2}{|c|}{$\begin{array}{l}\text { Myocardial } \\
\text { ischemia } \\
\text { time }\end{array}$} \\
\hline & Preop & $\begin{array}{c}2 \mathrm{~h} \text { after } \\
\text { bypass }\end{array}$ & $\begin{array}{c}24 \mathrm{~h} \text { after } \\
\text { bypass }\end{array}$ & $\begin{array}{c}P \\
\text { value }\end{array}$ & Preop & $\begin{array}{c}2 \mathrm{~h} \text { after } \\
\text { bypass }\end{array}$ & $\begin{array}{c}24 \mathrm{~h} \text { after } \\
\text { bypass }\end{array}$ & $\begin{array}{c}P \\
\text { value }\end{array}$ & CCE & $\begin{array}{c}P \\
\text { value }\end{array}$ & CCE & $\begin{array}{c}P \\
\text { value } \\
\end{array}$ & CCE & $\begin{array}{c}P \\
\text { value } \\
\end{array}$ \\
\hline sE-selectin & & & & .05 & & & & .2 & -0.1 & .4 & 0.2 & .3 & 0.2 & .1 \\
\hline Mean \pm SE & $23.2 \pm 2.4$ & $36.9 \pm 6.4$ & $24 \pm 3.6$ & & $30.9 \pm 3.9$ & $43.2 \pm 5.4$ & $34.4 \pm 4.4$ & & & & & & & \\
\hline $\begin{array}{l}\text { Interquartile } \\
\text { range }\end{array}$ & 14.9-33.1 & $21.6-40$ & $16.6-27.8$ & & $14.9-37.2$ & 22-61.3 & $15.5-53.6$ & & & & & & & \\
\hline sP-selectin & & & & .1 & & & & .1 & -0.2 & .2 & -0.1 & .4 & -0.1 & .5 \\
\hline Mean \pm SE & $180.6 \pm 22.1$ & $172 \pm 25.2$ & $121.8 \pm 13$ & & $208.5 \pm 30$ & $208.5 \pm 32.7$ & $135.6 \pm 21.2$ & & & & & & & \\
\hline $\begin{array}{l}\text { Interquartile } \\
\text { range }\end{array}$ & $102-224.4$ & 91.3-193.3 & 82.4-157.4 & & $95.8-282.8$ & $84.6-242.8$ & $55.4-171.3$ & & & & & & & \\
\hline IL-6 & & & & .0001 & & & & .0001 & 0.1 & .3 & 0.1 & .3 & 0.2 & .4 \\
\hline Mean \pm SE & $3 \pm 1.1$ & $76.5 \pm 6.4$ & $76.9 \pm 5.7$ & & $3.2 \pm 1$ & $81.8 \pm 6.1$ & $68.7 \pm 5.9$ & & & & & & & \\
\hline $\begin{array}{l}\text { Interquartile } \\
\text { range }\end{array}$ & $0.3-2.7$ & $38.4-100$ & $56.7-100$ & & $0.4-2.6$ & $76.5-100$ & 51.9-100 & & & & & & & \\
\hline IL-8 & & & & .0001 & & & & .0001 & 0.1 & .4 & 0.04 & .8 & 0.1 & .6 \\
\hline Mean \pm SE & $11.6 \pm 2$ & $61.9 \pm 11.4$ & $22.3 \pm 13.2$ & & $8.6 \pm 1.4$ & $60.3 \pm 9.2$ & $24.2 \pm 2.2$ & & & & & & & \\
\hline $\begin{array}{l}\text { Interquartile } \\
\text { range }\end{array}$ & $5.2-13.5$ & $23.97-93.6$ & $12.9-27.9$ & & $2.4-10.4$ & $30.5-72.4$ & $14.5-35.1$ & & & & & & & \\
\hline ICAM-1 & & & & .02 & & & & .01 & -0.1 & .3 & -0.2 & .3 & -0.05 & .7 \\
\hline Mean \pm SE & $342.2 \pm 26$ & $267.2 \pm 15.5$ & $336.1 \pm 18.2$ & & $372.2 \pm 23.8$ & $294.3 \pm 22.6$ & $431.4 \pm 42$ & & & & & & & \\
\hline $\begin{array}{l}\text { Interquartile } \\
\text { range }\end{array}$ & 219.1-421 & 214.1-329.4 & 258.7-414.6 & & 277.7-471 & $214.6-362.2$ & $279.5-522.2$ & & & & & & & \\
\hline CD18 & & & & .001 & & & & .1 & -0.009 & .9 & 0.2 & .1 & 0.2 & .2 \\
\hline Mean \pm SE & $63.6 \pm 3.6$ & $83.8 \pm 3.4$ & $80.5 \pm 4.7$ & & $63.3 \pm 4.1$ & $77.5 \pm 4.7$ & $71.9 \pm 4.8$ & & & & & & & \\
\hline $\begin{array}{l}\text { Interquartile } \\
\text { range }\end{array}$ & $49.5-80.3$ & $66.6-96.6$ & $60.3-95.1$ & & $47.2-81.2$ & 58.5-93.7 & $46.6-91.8$ & & & & & & & \\
\hline TNF- $\alpha$ & & & & .0001 & & & & .001 & -0.005 & .9 & 0.1 & .3 & 0.2 & .1 \\
\hline Mean \pm SE & $21.1 \pm 2.5$ & $47.3 \pm 7.1$ & $22.4 \pm 3$ & & $27.5 \pm 3.4$ & $54.8 \pm 9.3$ & $26.4 \pm 3.1$ & & & & & & & \\
\hline $\begin{array}{l}\text { Interquartile } \\
\text { range }\end{array}$ & $13.8-25.7$ & $22.4-63.7$ & $14.3-28.1$ & & $18.3-32.7$ & $21.1-78.7$ & $18.5-34.8$ & & & & & & & \\
\hline HSP-70 & & & & .007 & & & & .2 & 0.1 & .7 & 0.6 & .02 & 0.7 & .006 \\
\hline Mean \pm SE & $8.1 \pm 1$ & $19.7 \pm 4.5$ & $8.9 \pm 1$ & & $7.6 \pm 1.4$ & $14 \pm 2.8$ & $11.9 \pm 2$ & & & & & & & \\
\hline $\begin{array}{l}\text { Interquartile } \\
\text { range }\end{array}$ & $6.1-9.2$ & $11.8-33.8$ & $6.7-10.3$ & & 5-10.2 & $6.8-21$ & 7.3-16.1 & & & & & & & \\
\hline
\end{tabular}

Preop, Preoperative; $C P B$, cardiopulmonary bypass; $C C E$, correlation coefficient; $s E$-selectin, soluble E-selectin; $s P$-selectin, soluble P-selectin; IL, interleukin; $I C A M$, intercellular adhesion molecule; $T N F$, tumor necrosis factor; $H S P$, heat shock protein.

was significant in both groups, whereas that of sP selectin was not significant in either group. Spearman correlation analysis (Table 2) revealed a significant direct correlation between the postoperative increase in HSP-70 and the duration of cardiopulmonary bypass $(P=.02)$ and myocardial ischemia $(P=.006)$. Such a correlation was not noted with the rest of the inflammatory molecules.

The test-retest interval, verbal (Wechsler Test of Adult Reading score) and nonverbal (Raven matrices) IQ, and HADS results were comparable (Table 1). Table 3 shows the group mean scores and standard deviations in individual neuropsychometric tests and the deterioration in performance using the standard deviation index method. A total of 16 patients in group A had significant neuropsychometric dysfunction, compared with 9 patients in group B $(P=.05)$. None of the tested variables-age, sex, left ventricular function, cardiopulmonary bypass time, myocardial ischemia time, verbal and nonverbal IQ, HADS results, or postoperative increase in inflammatory markers-were predictors of neuropsychometric decline on logistic regression analysis.

\section{Discussion}

Coronary artery bypass surgery is one of the most frequently performed operations worldwide. Despite advances, there is still a significant risk of brain injury inherent to the procedure. In addition, the inflammatory response plays an important role in progressive organ damage and perioperative morbidity. Hyperbaric oxygen has been shown to induce central nervous system ischemic tolerance ${ }^{5-8}$ in animal studies and also to reduce the inflammatory response ${ }^{9-19}$ in animal and human studies. Although the precise mechanism 
TABLE 3. Comparison of neuropsychometric test performance

\begin{tabular}{|c|c|c|c|c|c|c|}
\hline \multirow[b]{2}{*}{ Neuropsychometric tests } & \multicolumn{3}{|c|}{ Group A } & \multicolumn{3}{|c|}{ Group B } \\
\hline & Preop score & Postop score & $\begin{array}{c}\text { Patients with } \\
\begin{array}{c}>1 \text { SD } \\
\text { decline }\end{array}\end{array}$ & Preop score & Postop score & $\begin{array}{c}\text { Patients with } \\
>1 \mathrm{SD} \\
\text { decline }\end{array}$ \\
\hline Trail making $A$ & & & 2 & & & 4 \\
\hline Mean $\pm S D$ & $41.7 \pm 14.9$ & $40.6 \pm 15.7$ & & $43 \pm 16.3$ & $41.4 \pm 15.5$ & \\
\hline Interquartile range & $30.5-55$ & $30-47.5$ & & $31-50$ & $29.8-55.3$ & \\
\hline Trail making $B$ & & & 3 & & & 2 \\
\hline Mean \pm SE & $101 \pm 43.5$ & $107 \pm 54.7$ & & $127.1 \pm 52.6$ & $108.7 \pm 45.5$ & \\
\hline Interquartile range & $67-109.5$ & $69-132.5$ & & $89.3-158.5$ & $69.5-134$ & \\
\hline Grooved pegboard, dominant hand & & & 6 & & & 4 \\
\hline Mean \pm SE & $19.1 \pm 2.2$ & $19.1 \pm 2.6$ & & $19.7 \pm 2.8$ & $19.1 \pm 2.5$ & \\
\hline $\begin{array}{l}\text { Interquartile range Grooved } \\
\text { pegboard, nondominant hand }\end{array}$ & 17.5-20.9 & $17-20.9$ & & $17.5-21.6$ & $17-20$ & \\
\hline Mean \pm SE & $21 \pm 2.3$ & $20.4 \pm 2.6$ & & $21.1 \pm 3$ & $20.9 \pm 3.7$ & \\
\hline Interquartile range & $19.1-22.5$ & $18.5-21.9$ & & $18.8-22$ & $19-23$ & \\
\hline $\begin{array}{l}\text { Rey auditory verbal learning test } \\
\text { Total recall (attempts } 1-5 \text { ) }\end{array}$ & & & 19 & & & 10 \\
\hline Mean \pm SE & $41.2 \pm 9.6$ & $40.6 \pm 10.4$ & & $37.8 \pm 11.5$ & $39.4 \pm 11$ & \\
\hline $\begin{array}{l}\text { Interquartile range } \\
\text { Immediate recall }\end{array}$ & $34.5-47.5$ & $33-48.5$ & & 29-47.3 & $32-45.3$ & \\
\hline Mean \pm SE & $8.1 \pm 3.3$ & $7.8 \pm 3$ & & $7.5 \pm 2.7$ & $7.5 \pm 3.5$ & \\
\hline $\begin{array}{l}\text { Interquartile range } \\
\text { Delayed recall }\end{array}$ & $5-11$ & $5-10$ & & $6-8.3$ & $6-10.3$ & \\
\hline Mean $\pm S E$ & $8.4 \pm 3.5$ & $7.7 \pm 3$ & & $7.6 \pm 3.6$ & $7.9 \pm 3.2$ & \\
\hline $\begin{array}{l}\text { Interquartile range } \\
\text { Recognition }\end{array}$ & $6-12$ & $5-10$ & & $5-9.3$ & $5.8-10.3$ & \\
\hline Mean \pm SE & $11.8 \pm 2.8$ & $12.1 \pm 2.3$ & & $11.4 \pm 2.7$ & $12.4 \pm 1.9$ & \\
\hline Interquartile range & $10-14.8$ & $11-13.8$ & & $10-14$ & $11-14$ & \\
\hline $\begin{array}{l}\text { Adult memory and information } \\
\text { processing, Table A }\end{array}$ & & & 3 & & & 4 \\
\hline Mean $\pm S E$ & $59 \pm 14.6$ & $61.1 \pm 15.1$ & & $52.9 \pm 15.8$ & $55.5 \pm 13.7$ & \\
\hline Interquartile range & $48-69.5$ & $49-73.5$ & & $43-61$ & $47.5-60.5$ & \\
\hline Digit span forward & & & 6 & & & 5 \\
\hline Mean $\pm S E$ & $9.9 \pm 2.7$ & $9.5 \pm 2.6$ & & $8.9 \pm 2.3$ & $9.2 \pm 2.5$ & \\
\hline Interquartile range & $7.3-12$ & $8-11$ & & $7.8-11$ & $7.8-11$ & \\
\hline Digit span backward & & & 10 & & & 5 \\
\hline Mean \pm SE & $6.8 \pm 2.5$ & $6.3 \pm 2.2$ & & $5.9 \pm 2.1$ & $6.1 \pm 2.1$ & \\
\hline Interquartile range & $5-8.8$ & 5-8 & & $4.8-7$ & $5-8$ & \\
\hline
\end{tabular}

Significant neuropsychometric dysfunction ( $>1$ SD decline in $>2$ tests) occurred in 16 patients in group A and 9 patients in group B (P $=.05)$. Preop, Preoperative; Postop, postoperative.

of action is still unclear and continues to be investigated, the purported effectiveness and relative safety of the modality makes it potentially applicable in cardiac surgery.

We performed a broad analysis of cytokines, adhesion molecules, and stress response proteins to gain an insight into the induction, propagation, and stress response phases of the inflammatory cascade. The selection of markers was also based on a review of the published literature ${ }^{9-19}$ and the availability, reproducibility, sensitivity, specificity, and cost-effectiveness of the tests. The main difference between this study and previously published work using hyperbaric oxygen as a modulator of inflammatory response is that our main trigger for inflammation was extracorporeal circulation and not sepsis, shock, or ischemia. Species-specific differences, trigger-specific variation in inflammatory response within the same species, ${ }^{24,25}$ and the effects of medications such as aspirin, ${ }^{26}$ statins,${ }^{27}$ and angiotensin-converting enzyme inhibitors $^{28}$ are potential reasons why the trend in certain markers such as CD18 correlated with the findings of previous work, whereas others, such as TNF- $\alpha$, IL-6, and ICAM-1, did not. Despite the significantly higher postoperative levels in sEselectin, CD18, and HSP-70 in group A, the overall trend in the rise and fall of all the measured markers was similar in both groups. Thus, the effect of hyperbaric oxygen was 
limited to reducing the amplitude of the inflammatory response-not annulling it. The significant correlation between HSP-70, cardiopulmonary bypass time, and myocardial ischemia time is consistent with the acute stress response nature of the protein. ${ }^{29,30}$

Analyzing the dive pressures used in the study, it is clear that group A was not a true placebo because the oxygen percentage in air at 1.5 ATA pressure is equivalent to $30 \%$. However, this was a necessary compromise to preserve the double-blind nature of the trial. The slightly higher than atmospheric pressure was necessary so that patients in the control group heard pressurization sounds and felt ear pressure changes similar to those that patients in group B heard and felt. If we had used diluted air to make a true placebo, ie, patient breathing $21 \%$ oxygen at 1.5 ATA, then the increase in nitrogen in the air mix would certainly increase the risk of decompression illness. This was minimized by the safe protocol we used, ie, true air at depth. Of importance is the absence of any significant effect on infarct volume $^{5-8}$ and inflammatory mediators ${ }^{9-19}$ by air at less than 2 ATA noted in previous studies.

Neuropsychometric examination is a time-tested method of identifying cognitive dysfunction resulting from brain injury. Despite the advent of functional magnetic resonance imaging scanning, when performed by trained individuals, neuropsychometric examination is still a reliable and reproducible way of identifying, assessing, and measuring brain injury. In choosing the neuropsychometric test battery, our aim was to perform a global assessment of different domains within an optimum time period without mentally fatiguing the patient. The main problem during analysis and interpretation of the neuropsychometric test results of a group is the effect of practice and learning during repeat testing. Just like the proportion of patients whose performance and scores decline, a proportion of patients will do the opposite and score higher. Although by using alternate forms of the same test and limiting the number of repeat tests, this practice effect can be reduced, it cannot be completely eliminated. This effect becomes evident on comparing the group means (Table 3): in the Trail Making B test, there was a significant improvement in group $\mathrm{B}(P=.01)$ performance, compared with a deterioration in group A $(P=.4)$. Comparing the overall group mean loses its relevance in a study aimed at preventing or reducing neuropsychometric decline. We used the standard deviation index method to exclude the effect of this phenomenon. Using this method, we found that significantly $(P=.05)$ more patients in group A had neuropsychometric impairment compared with group B (Table 3). None of the tested variables-age, sex, left ventricular function, cardiopulmonary bypass time, myocardial ischemia time, IQ, mood, or postoperative increase in inflammatory markers-was a predictor of neuropsychometric decline on logistic regression analysis.
The main limitation of this study is that it was based on a small sample of low-risk patients at a single center. Arguably this allows reproducibility, and one cannot generalize the findings of this study. Only a prospective randomized controlled multicenter trial would provide the solution to this argument. The operative and perioperative factors were standardized as much as possible; however, one factor that could have a bearing on neuropsychometric outcome is the distribution of atherosclerotic plaques within the ascending aorta. Patients with peripheral vascular disease were excluded from the study, and the surgeons externally palpated the aorta and avoided any areas of plaque during clamping of the aorta; however, this is not a foolproof method. Perhaps epiaortic Doppler scanning or transesophageal echocardiography would have been a better way of detecting aortic atherosclerosis. We performed only a single postoperative neuropsychometric assessment at 4 months. This was to minimize the practice effect, exclude the effect of postoperative recovery and medications on early assessment, and exclude the effect of new but unrelated cerebral events on delayed assessment. Despite standardization of the anesthetic techniques and drugs used, possible variations in dosage, patient metabolism, and elimination of the different drugs are inevitable. The time lapse between operation and assessment would have certainly allowed for any direct cerebral effects of the anesthetic medications to be eliminated. Although the outcome at 4 months is an indication of the long-term neuropsychometric dysfunction, it may not necessarily reflect permanent sequelae from the initial brain injury. Of importance is the fact that any human study of this nature precludes neuronal evaluation. Enzyme induction or inhibition, free radical release, antioxidant status, and protein synthesis are illunderstood aspects of the mechanism of action that can be evaluated only through in vitro studies or animal models.

This was one of the first human trials of this nature, and further prospective randomized multicenter trials are necessary to confirm the findings of this study. The cost of 1 hyperbaric oxygen treatment session was $£ 50$, and our use of 3 sessions was based on previous animal studies; however, if further trials reveal a consistent effect with 1 session, the technique becomes more cost-effective and clinically feasible in high-risk cases. Neuropsychometric dysfunction does not necessarily prolong hospitalization or add to the immediate cost of treatment, but it has a considerable effect on a patient's memory, behavior, interactive ability, and socioeconomic circumstances.

In conclusion, although this study revealed that pretreating patients with hyperbaric oxygen reduces the postoperative inflammatory response and neuropsychometric dysfunction, the actual mechanism underlying this beneficial effect is still unclear. Pursuing cellular-level changes in enzyme induction or inhibition, free radical release or inhi- 
bition, antioxidant status, and protein synthesis may hold the answer and is an area for further research.

We thank John Greenman, PhD, Senior Lecturer, Department of Immunology, University of Hull, and Suniti Mandana, PhD, Senior Lecturer, Department of Neuropsychology, University of Hull. We also thank Air-Products for the material help and BUPA Hospital in Hull for allowing us to use their hyperbaric chamber.

\section{References}

1. Connolly ES Jr, Winfree CJ, Prestigiacomo CJ, Kim SC, Choudhri TF, Hoh BL, et al. Exacerbation of cerebral injury in mice that express the P-selectin gene: identification of P-selectin blockade as a new target for the treatment of stroke. Circ Res. 1997;81:304-10.

2. Matsuo Y, Onodera H, Shiga Y, Shozuhara H, Kogure K. Role of cell adhesion molecules in brain injury after transient middle cerebral artery occlusion in the rat. Brain Res. 1994;656:344-52.

3. Huang J, Choudhri TF, Winfree CJ, McTaggart RA, Kiss S, Mocco J, et al. Postischemic cerebrovascular E-selectin expression mediates tissue injury in murine stroke. Stroke. 2000;31:3047-53.

4. Chopp M, Li Y, Jiang N, Zhang RL, Prostak J. Antibodies against adhesion molecules reduce apoptosis after transient middle cerebral artery occlusion in rat brain. J Cereb Blood Flow Metab. 1996;16:578-84.

5. Wada K, Miyazawa T, Nomura N, Tsuzuki N, Nawashiro H, Shima K. Preferential conditions for and possible mechanisms of induction of ischemic tolerance by repeated hyperbaric oxygenation in gerbil hippocampus. Neurosurgery. 2001;49:160-7.

6. Prass K, Wiegand F, Schumann P, Ahrens M, Kapinya K, Harms C, et al. Hyperbaric oxygenation induced tolerance against focal cerebral ischemia in mice is strain dependent. Brain Res. 2000;871:146-50.

7. Dong H, Xiong L, Zhu Z, Chen S, Hou L, Sakabe T. Preconditioning with hyperbaric oxygen and hyperoxia induces tolerance against spinal cord ischemia in rabbits. Anesthesiology. 2002;96:907-12.

8. Miljkovic-Lolic M, Silbergleit R, Fiskum G, Rosenthal RE. Neuroprotective effects of hyperbaric oxygen treatment in experimental focal cerebral ischemia are associated with reduced brain leukocyte myeloperoxidase activity. Brain Res. 2003;97:90-4.

9. Tjarnstrom J, Wikstrom T, Bagge U, Risberg B, Braide M. Effects of hyperbaric oxygen treatment on neutrophil activation and pulmonary sequestration in intestinal ischemia-reperfusion in rats. Eur Surg Res. 1999;31:147-54.

10. Yang ZJ, Bosco G, Montante A, Ou XI, Camporesi EM. Hyperbaric oxygen reduces intestinal ischemia reperfusion induced TNF-alpha production and lung neutrophil sequestration. Eur J Appl Physiol. 2001;85:96-103.

11. Yamashita M, Yamashita M. Hyperbaric oxygen treatment attenuates cytokine induction after massive haemorrhage. Am J Physiol Endocrinol Metab. 2000;278:E811-6.

12. Benson RM, Minter LM, Osborne BA, Granowitz EV. Hyperbaric oxygen inhibits stimulus induced proinflammatory cytokine synthesis by human blood-derived monocyte-macrophages. Clin Exp Immunol. 2003;134:57-62.

13. Weisz G, Lavy A, Adir Y, Melamed Y, Rubin D, Eidelman S, et al. Modification of in vivo and in vitro TNF-alpha, IL-1, and IL-6 secretion by circulating monocytes during hyperbaric oxygen treatment in patients with perianal Crohn's disease. J Clin Immunol. 1997;17:154-9.

14. Buras JA, Stahl GL, Svoboda KS, Reenstra WR. Hyperbaric oxygen down-regulates ICAM-1 expression induced by hypoxia and hypoglycemia; role of eNOS. Am J Physiol Cell Physiol. 2000;278:C292-302.

15. Hong JP, Kwon H, Chung YK, Jung SH. The effect of hyperbaric oxygen on ischemia-reperfusion injury: an experimental study in a rat musculocutaneous flap. Ann Plast Surg. 2003;51:478-87.

16. Thom SR, Mendiguren I, Hardy K, Bolotin T, Fisher D, Nebolon M, et al. Inhibition of human neutrophil beta-2 integrin dependent adherence by hyperbaric oxygen. Am J Physiol. 1997;272:C770-7.

17. Kalns J, Lane J, Delgado A, Scruggs J, Ayala E, Gutierrez E, et al. Hyperbaric oxygen exposure temporarily reduces Mac-1 mediated functions of human neutrophils. Immunol Lett. 2002;83:125-31.

18. Cuzzocrea S, Imperatore F, Costantino G, Luongo C, Mazzon E, Scafuro MA, et al. Role of hyperbaric oxygen exposure in reduction of lipid peroxidation and multiple organ failure induced by zymosan administration in the rat. Shock. 2000;13:197-203.

19. Chen MF, Chen HM, Ueng SW, Shyr MH. Hyperbaric oxygen pretreatment attenuates hepatic reperfusion injury. Liver. 1998;18:110-6.

20. Roth-Isigkeit A, Borstel TV, Seyfarth M, Schmucker P. Perioperative serum levels of tumour necrosis factor alpha, IL-1beta, IL-6, IL-10, and soluble IL-2 receptor in patients undergoing cardiac surgery with cardiopulmonary bypass without and with correction for hemodilution. Clin Exp Immunol. 1999;118:242-6.

21. Murkin JM, Newman SP, Stump DA, Blumenthal JA. Statement of consensus on assessment of neurobehavioral outcomes after cardiac surgery. Ann Thorac Surg. 1995;59:1289-95.

22. Newman MF, Kirchner JL, Phillips-Bute B, Gaver V, Grocott H, Jones $\mathrm{RH}$, et al. Neurological Outcome Research Group and the Cardiothoracic Anesthesiology Research Endeavors Investigators. Longitudinal assessment of neuropsychometric function after coronary-artery bypass surgery. N Engl J Med. 2001;344:395-402.

23. Zamvar V, Williams D, Hall J, Payne N, Cann C, Young K, et al. Assessment of neuropsychometric impairment after off-pump and on-pump techniques for coronary artery bypass graft surgery: prospective randomised controlled trial. BMJ. 2002;325:1-5.

24. Denizot Y, Lorgeot V, Cornu E, Nathan N. Plasma leukaemia inhibitory factor interleukin 6 and soluble interleukin 6 receptor levels during cardiopulmonary bypass with extracorporeal circulation. Cytokine. 1998;10:303-6.

25. Boldt J, Kumle B, Papsdorf M, Hempelmann G. Are circulating adhesion molecules specifically changed in cardiac surgical patients? Ann Thorac Surg. 1998;65:608-14.

26. Bates JJ, Watson RW, Glynn CM, O’Neil AJ, Fitzpatrick JM, Buggy DJ. Aspirin preserves neutrophil apoptosis after cardiopulmonary bypass. Shock. 2004;21:495-9.

27. van Haelst PL, Tervaert JW, van Geel PP, Veeger NJ, Gurne O, Gans $\mathrm{RO}$, et al. Long term angiotensin converting enzyme inhibition in patients after coronary artery bypass grafting reduces levels of soluble intercellular cell adhesion molecule-1. Eur J Vasc Endovasc Surg. 2003;26:387-91

28. Chello M, Carassiti M, Agro F, Mastroroberto P, Pugliese G, Colonna $\mathrm{D}$, et al. Simvastatin blunts the increase of circulating adhesion molecules after coronary bypass surgery with cardiopulmonary bypass. J Cardiothorac Vasc Anesth. 2004;18:605-9.

29. Schmitt JP, Schunkert H, Birnbaum DE, Aebert H. Kinetics of heat shock protein 70 synthesis in the human heart after cold cardioplegic arrest. Eur J Cardiothorac Surg. 2002;22:415-20.

30. Demidov ON, Tyrenko VV, Svistov AS, Komarova YY, Karpishenko AI, Margulis BA, et al. Heat shock proteins in cardiosurgery patients. Eur J Cardiothorac Surg. 1999;16:444-9.

\section{Discussion}

Dr William A. Baumgartner (Baltimore, $M d$ ). I congratulate $\mathrm{Mr}$ Alex and his associates for conducting a randomized prospective double-blind study evaluating the use of hyperbaric oxygen and its efficacy in reducing neurocognitive dysfunction after cardiopulmonary bypass. As he mentioned, the patients, surgeons, and neuropsychologists were all blinded to the study groups. The results are fairly straightforward in that there was no significant difference in any clinical postoperative variable other than neurocognitive dysfunction, which was significantly better in the patients who received hyperbaric oxygen treatment. There is a growing body of both experimental and some clinical studies, as pointed out by the authors, using hyperbaric oxygenation to reduce particularly focal cerebral ischemia associated with a stroke. This area of research has been somewhat controversial for a number of years.

One of the potential beneficial mechanisms of action of hyperbaric oxygen is the reduction in the inflammatory response. Although you showed a statistical reduction in a few markers in the treated group, many markers showed no change 
between groups. Would you please speculate on what might be the primary neuroprotectant mechanism associated with hyperbaric oxygen?

We and now others have demonstrated by using a controlled cohort of patients with similar risk factors that there does not seem to be any significant difference in the incidence of neurocognitive decline at 3 months or at 1 year, and now recently 3 years, between patients undergoing traditional coronary artery bypass grafting with the pump and those control patients who had undergone catheterization and/or angioplasty. This suggests that the decline may be more associated with cardiac risk factors rather than an operation which occurred a year ago. Would you please speculate and comment on using a control group of patients with similar risk factors who could undergo hyperbaric oxygen treatment but no operation and subsequent study 4 months later?

I was also wondering, since limiting aortic manipulation has been targeted as a potential method to reduce neurologic injury, was there a difference between groups as to the number of times the aorta was manipulated with the clamp?

Once again, I congratulate the authors for carrying out a randomized controlled double-blinded study and agree with them that further studies are needed to help define the efficacy of hyperbaric oxygen treatment.

Mr Alex. Coming to the first question, as mentioned in the presentation, following ischemia, extension of an infarct is mediated to a significant extent by leukocyte addition, degranulation, and free radical release. The mechanism of hyperbaric neuroprotection seems to be 2-pronged in limiting the leukocyte endothelial addition and, on the other side, augmenting antioxidant defenses. Though we showed a reduction in soluble E-selectin and CD18, consistent animal data and human data have shown that other studies have seen a reduction in the other inflammatory molecules that we analyzed, soluble ICAM-1 and P-selectin, and also the inflammatory markers IL-6, IL- 8 , and TNF- $\alpha$. The modality also augments superoxide dismutase levels and inhibits neuronal nitric oxide synthetase.

Regarding the second query, yes, these are the preliminary results of an ongoing trial, and the phase II trial includes 3 additional groups: a nonsurgical noncardiac group, a nonsurgical cardiac group, and a noncardiac general surgical group, each matched.

Going back to the point of neurocognitive dysfunction, there are 2 aspects of brain injury, the quantitative and the functional aspects. Transcranial Doppler and magnetic resonance imaging scans have shown that quantitatively there is an increase in microembolic load and microinfarct, cortical microinfarct, following the procedure, and subsequent studies have shown a coordination between the magnitude of the microemboli and cortical infarcts to subsequent early neurocognitive dysfunction in these patients.

Though neurocognitive dysfunction measures neurocognitive assessment, though it measures the functional aspect, it does not account for the compensation by the normal cortex for subcritical ischemic infarcts. For want of a better end point, we used neurocognitive assessment in this trial to test whether the modality would improve the outcome following brain injury.

Coming to the third point, yes, aortic manipulation was different between the 2 groups. The hyperbaric group, in fact, had a higher number of grafts, 3 grafts; $63 \%$ in the hyperbaric group had 3 grafts, compared to $43 \%$. Given the technique we used, which was crossclamp fibrillation, aortic manipulation was definitely higher. And $16 \%$ of the patients in the control group had single grafts, which were basically left internal thoracic artery to left anterior descending artery, which did not need aortic side clamp application.

Dr Richard Anderson (Seattle, Wash). My institution in Seattle has recently expanded its hyperbaric capability, and I am sure that those involved will be very pleased to read your paper when it comes out. There are skeptics that still say that this is a therapy in pursuit of a disease, but I hope you are right.

I do have one concern. Some years ago, Alan Hall, one of my colleagues, did a study of neurocognitive function accompanied by brain scans before and after operation, and amongst the interesting observations in this study was the fact that in otherwise cognitively normal individuals preoperatively, there are often a number of abnormalities that are noted in the brain scan. Now, in some individuals, these increase following surgery, as you would expect from the small embolic consequences and so forth, but the other observation was that regardless of the changes postoperatively in the brain scan, those individuals with abnormal studies preoperatively showed the largest cognitive declines in postoperative study.

So my question to you is, is it conceivable that failure to control for an underlying structural abnormality in the brain could have biased your study regardless of the fact that it was a randomized study? And perhaps if you are going to continue with these studies, is there some way to address this issue?

Mr Alex. Yes, we did exclude patients with a history of cerebrovascular disease. This was basically because this was a phase I trial, and the next phase includes patients who are at high risk for neurocognitive dysfunction. That includes patients with diabetes and hypertension, who were in this study, but also patients with previous cerebrovascular accidents and carotid artery disease. So we are in the process of addressing that.

Dr Hillel Laks (Los Angeles, Calif). I just wanted to recall the experience that we had with Dr Bill Burnhart when I was a resident, who was still doing closed heart procedures in a hyperbaric chamber to try and prevent neurologic injury.

I had a question for you. Did you have the opportunity of treating any patients postoperatively after they had a neurologic event, and is there any evidence that this might improve the recovery?

Mr Alex. Certainly, since the trial we have treated 3 patients so far, but these patients weren't part of the trial. This was based on the outcome of this trial, and their improvement was definitely better. The mechanism for postoperative hyperbaric treatment is slightly different from what the pre-treatment modality is. The normal soluble oxygen is about $0.3 \mathrm{~mL} / 100 \mathrm{~mL}$ of blood, whereas with hyperbaric oxygenation (at pressures used in this study), this goes up to $6.8 \mathrm{~mL} / 100 \mathrm{~mL}$ of blood. That is the soluble oxygen in the plasma. This increases the tissue penetration of oxygen, which appears to be one reason why patients post infarct recover so quickly with this modality. Yes, we have had patients who have been treated with hyperbaric oxygen post infarct. 